\title{
Determination of Tin in Copper Alloys and Solders by Inductively Coupled Plasma Atomic Emission Spectrometry with Tin Oxide Introduction
}

\author{
Yoshinobu YAMAмOTo and Junji Noro \\ Research Department, Nissan ARC Ltd., Natsushima, Yokosuka, Kanagawa 237, Japan
}

Keywords Inductively coupled plasma atomic emission spectrometry, tin oxide, copper alloy, solder

Recently, bronze has been used directly without any lubricant at the frictional surface of some automobile or air-conditioner parts. However, tin in the bronze tends to be oxidized due to frictional heat. Tin in the solder used in electronic parts is also oxidized due to heat during use. Although a potassium iodide titration method ${ }^{1}$ or ammonium iodide melting methods $\mathrm{s}^{2,3}$ can be used to determine the tin content of bronzes or solders, even when the tin is oxidized, the analytical procedures are so complicated that a rapid determination is difficult. Yoshimura et al. proposed a method whereby oxides of zinc or other metals are dispersed in water and directly introduced into an atomic absorption spectrometer. ${ }^{4-6}$ They applied this method to an analysis of tin oxide. ${ }^{7}$ One drawback of this method is that it gives different absorption values, depending on the oxidized state of the tin being examined. Furthermore, this method has not been applied to the determination of tin in various alloys. It has been reported that inductively coupled plasma atomic emission spectrometry (ICP-AES) can provide a rapid and accurate determination of tin and other elements in alloys containing tin. ${ }^{8,9}$ However, this technique cannot be applied when tin is oxidized without the use of special procedures, such as the laser abrasion method. ${ }^{10}$

In the present study, tin in brasses, bronzes, and solders was determined by a method whereby particles of tin oxide were introduced directly into ICP-AES. The precision of this method was also examined by using it to analyze other elements in these alloys simultaneously. Since particles of tin oxide were directly introduced into ICP-AES, which combined with a meinhard-type nebulizer in this method, they tended to clog the nebulizer with a normal diameter $(15-25 \mu \mathrm{m})$. To prevent clogging, a meinhard-type nebulizer with a larger diameter $(30 \mu \mathrm{m})$ was fabricated for use in the analysis. Furthermore, the sample solution was ultrasonically dispersed as it was introduced into ICP-AES in order to keep the dispersion of tin oxide precipitates uniform during a measurement.

\section{Experimental}

\section{Apparatus and reagents}

A Seiko Instruments Inc. (Model SPS-4000) inductively coupled plasma atomic emission spectrometer was used for the determination of elements. The operating conditions were similar to those used for the analysis of solution samples, except that a nebulizer with a diameter of $30 \mu \mathrm{m}$ was used. A Horiba Ltd. (Model LA-910) laser scattering particle-size distribution analyzer was used to determine the particle size of tin oxide. An Iuchi Co. (Model US-50R) ultrasonic generator was used to disperse the tin oxide particles in the solution. All of the reagents were of reagent grade. A standard stock solution of tin was prepared by dissolving tin metal $(99.99 \%$ Nacalai Tesque, Inc.) in 6 mol $\mathrm{dm}^{-3}$ hydrochloric acid, and then warming and diluting the solution with water. Solutions of suitable concentrations were prepared by dilution with $1 \mathrm{~mol}$ $\mathrm{dm}^{-3}$ hydrochloric acid before use. Standard stock solutions of the other elements were also prepared from high-purity metals or compounds.

\section{Procedure}

The tin metal, brass, bronze, and solder samples were dissolved by adding $20 \mathrm{ml}$ of $7 \mathrm{~mol} \mathrm{dm}^{-3}$ nitric acid in a tall form beaker (capacity $20 \mathrm{ml}$ ). If other components in the samples, except for tin oxide, could not be dissolved by this procedure, dilute hydrochloric acid was added. The solution was then heated at $423 \mathrm{~K}$ until the samples were dissolved and tin was oxidized. Then, 10 $\mathrm{ml}$ of concentrated perchloric acid was added and heated at $523 \mathrm{~K}$. This solution was heated until the water and nitric acid were evaporated and perchloric acid fumes appeared. The sample solution together with the tin oxide precipitates was cooled and diluted with water to a suitable concentration. This final sample solution was analyzed in order to determine the content of tin and other elements in the brass, bronzes, or solders by using ICP-AES combined with a large-diameter nebulizer. In order to keep the dispersion of tin oxide pre- 
cipitates uniform, the tin oxide particles in this final sample solution were dispersed by an ultrasonic technique during a measurement.

\section{Results and Discussion}

Reproducibility with the large-diameter nebulizer and memory effect

Test solutions containing $10 \mu \mathrm{g} \mathrm{ml}^{-1}$ of tin, lead, iron, manganese, zinc, phosphorus, and copper were measured in order to check the reproducibility of the results when the large-diameter nebulizer was used. The analytical results are given in Table 1. As can be seen from Table 1, the reproducibility (RSD: $n=15$ ) of each metal ion was less than $2.5 \%$. On the other hand, when a test solution containing $20 \mu \mathrm{g} \mathrm{ml}^{-1}$ of tin which was oxidized by perchloric acid was introduced directly into ICP-AES combined with this nebulizer, a memory effect was obtained, which was caused by bonding of the tin oxide particles to the nebulizer. It was found that this memory effect could be avoided by washing the nebulizer with a mixed solution of $6 \mathrm{~mol} \mathrm{dm}^{-3}$ hydrochloric acid and $7 \mathrm{~mol} \mathrm{dm}^{-3}$ nitric acid after each sample was measured. The reproducibility results obtained when the nebulizer was washed and when it was not washed are also given in Table 1.

\section{Effect of acid}

The effect of the acid on the determination of the tin content was examined when 20 to $300 \mathrm{mg}$ of tin was dissolved only in nitric acid and in both nitric and perchloric acid. The latter was heated at $523 \mathrm{~K}$ until the nitric acid was evaporated and perchloric acid fumes appeared. These solutions, together with the tin oxide precipitates, were diluted to $200 \mathrm{ml}$ with water. They were then measured by ICP-AES and compared with standard solutions which were prepared by dissolving tin metal in $6 \mathrm{~mol} \mathrm{dm}^{-3}$ hydrochloric acid. Figure 1 gives the relation between the total concentration of tin

Table 1 Reproducibility with a large-diameter nebulizer $(n=15)$

\begin{tabular}{lcc}
\hline & Av. value \pm S.D. $/ \mu \mathrm{g} \mathrm{ml}^{-1}$ & $\mathrm{RSD}, \%$ \\
\hline $\mathrm{Sn}$ & $9.92 \pm 0.14$ & 1.38 \\
$\mathrm{~Pb}$ & $9.86 \pm 0.16$ & 1.64 \\
$\mathrm{Fe}$ & $9.98 \pm 0.07$ & 0.68 \\
$\mathrm{Mn}$ & $10.0 \pm 0.06$ & 0.55 \\
$\mathrm{Zn}$ & $10.0 \pm 0.07$ & 0.74 \\
$\mathrm{P}$ & $9.85 \pm 0.20$ & 2.04 \\
$\mathrm{Cu}$ & $10.0 \pm 0.06$ & 0.59 \\
$\mathrm{SnO}_{2}{ }^{\mathrm{a}}$ & $196.4 \pm 3.4$ & 1.73 \\
$\mathrm{SnO}_{2}{ }^{\mathrm{b}}$ & $183.2 \pm 12.5$ & 6.84 \\
\hline
\end{tabular}

The concentraction of $\mathrm{Sn}, \mathrm{Pb}, \mathrm{Fe}, \mathrm{Mn}, \mathrm{Zn}, \mathrm{P}$, and $\mathrm{Cu}$ is 10.0 $\mu \mathrm{g} \mathrm{ml}^{-1}$ and that of $\mathrm{SnO}_{2}$ is $200 \mu \mathrm{g} \mathrm{ml}^{-1}$.

a. Washed by hydrochloric and nitric acid.

b. Without washing.

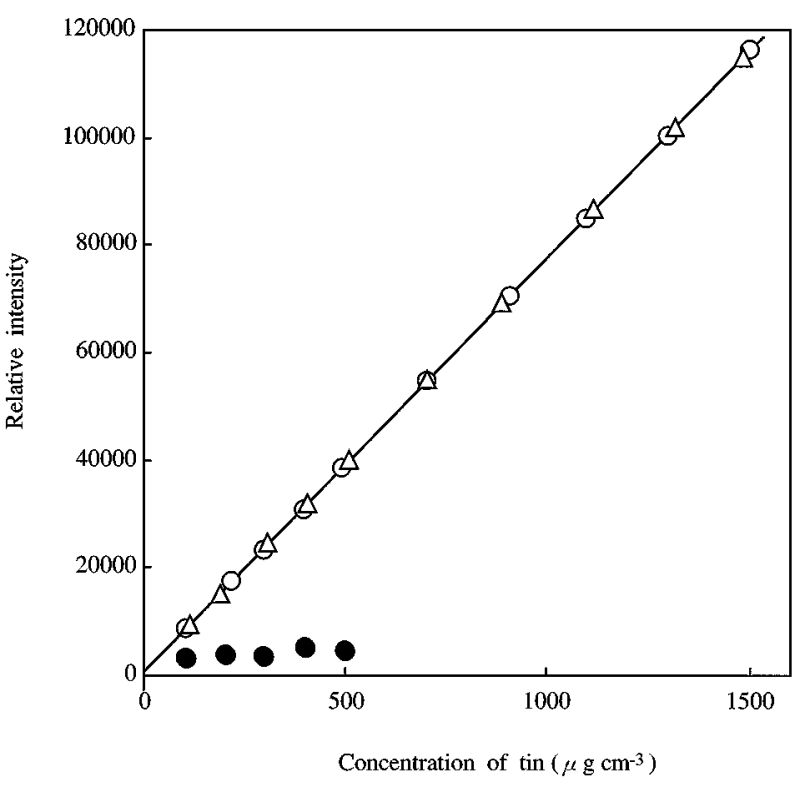

Fig. 1 Relation between the total concentration of tin and its relative intensity. $(\bullet)$ : only nitric acid; $(\Delta)$ : both nitric and perchloric acid; $(\mathrm{O})$ : only hydrochloric acid (standard solutions) used to dissolve tin.

and its relative intensity, as found by ICP-AES. The results obtained by dissolving tin in both nitric and perchloric acid agreed well with those for the standard solutions. However, when only nitric acid was used, the relative intensity was much lower than that of the standard solutions and that for tin dissolved in both nitric and perchloric acid. Furthermore, no clear relation between the concentration and the relative intensity was observed. In order to elucidate these phenomena, the particle-size distribution of tin oxide was deter-

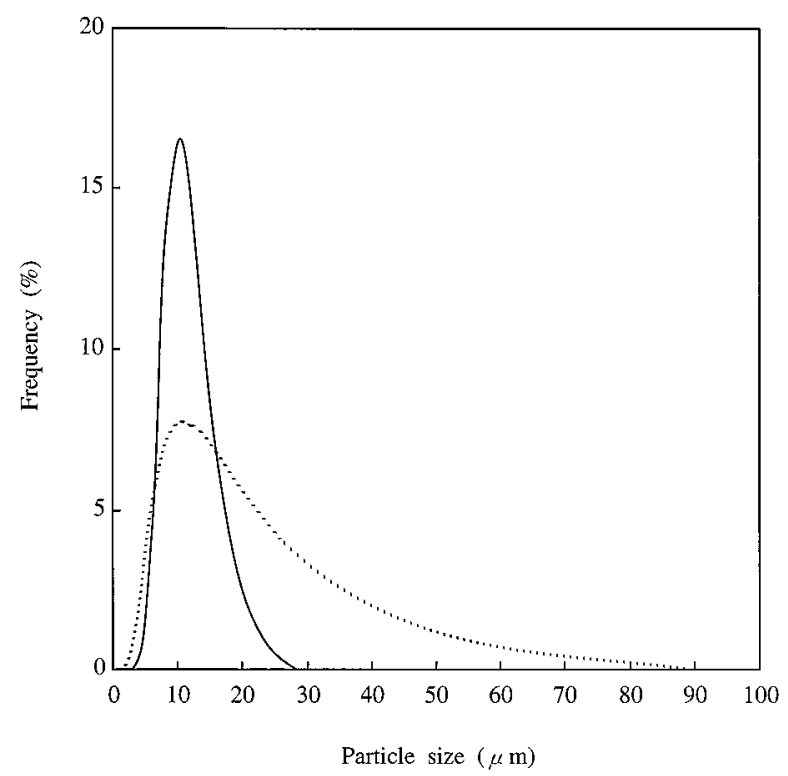

Fig. 2 Effect of acid on the particle-size distribution of tin oxide. The dotted line: only nitric acid; the solid line: both nitric and perchloric acid used to dissolve tin. 
mined with the laser scattering particle-size distribution analyzer. The obtained results are given in Fig. 2. As can be seen from Fig. 2, when both nitric and perchloric acid were used, the particle size of tin oxide was smaller than $30 \mu \mathrm{m}$. On the other hand, when only nitric acid was used, the size was much greater than that of the large-diameter nebulizer $(30 \mu \mathrm{m})$. Since the nebulizer should not have been clogged with tin oxide particles when the former method was used, the analytical results agreed well with those obtained for the standard solutions.

\section{Upper limit and detection limit for the determination of} tin oxide

As can be seen from Fig. 1, the calibration curve of tin, which was dissolved in both nitric and perchloric acid, was a straight line up to $1500 \mu \mathrm{g} \mathrm{ml}^{-1}$. Thus, the maximum amount of tin oxide that could be introduced into ICP-AES combined with the large-diameter nebulizer was $1500 \mu \mathrm{g} \mathrm{ml} \mathrm{m}^{-1}$. However, in order to avoid clogging the nebulizer with tin oxide particles, the upper limit for determination was defined as $500 \mu \mathrm{g}$ $\mathrm{ml}^{-1}$.

A test solution containing $10 \mu \mathrm{g} \mathrm{ml}^{-1}$ of tin oxide particles was measured by using ICP-AES combined with the large-diameter nebulizer. The detection limits, defined as the concentration of twice the standard deviation of the background signal, were calculated. The detection limit for tin oxide was found to be $0.15 \mu \mathrm{g}$ $\mathrm{ml}^{-1}$.

\section{Analysis of standard materials and practical samples}

The analytical results for the elements contained in the standard brass, bronzes, and solders and used bronzes and solder are given in Table 2. Tin in the used bronzes and solder was oxidized by heat and these tin concentrations were also analyzed by the potassium iodate titration method. The other elements in the used bronzes and solder were also analyzed by conventional methods specified in the Japanese Industrial Standards (JIS) or by the ICP-AES method after separation of the tin oxide precipitates. The certified values and those obtained by other methods are also listed in Table 2 . As can be seen from Table 2, the results obtained by the present method nearly agree with the certified values or those obtained by other methods. Although antimony was presumably oxidized by nitric and perchloric acids, resulting in the precipitation of antimony oxide, the data agree with the certified values. This suggests that antimony oxide could also be determined by this method in addition to tin oxide.

Using the method described here, even tin in an oxidized state can be measured much more rapidly and easily than with conventional methods. Furthermore, other elements in brass, bronze, and solder can also be determined simultaneously.

The authors are very grateful to Professor Tatsuya Sekine of Science University of Tokyo for his valuable discussions as well as to Mr. Yasushi Oki for the large-diameter nebulizer.

Table 2 Analytical results for elements in solders, bronzes, and brass (wt\%)

\begin{tabular}{|c|c|c|c|c|c|c|c|c|c|}
\hline & $\mathrm{Sn}$ & $\mathrm{Pb}$ & $\mathrm{Ni}$ & $\mathrm{P}$ & $\mathrm{Fe}$ & $\mathrm{Mn}$ & $\mathrm{Zn}$ & $\mathrm{Sb}$ & $\mathrm{Cu}$ \\
\hline \multicolumn{10}{|l|}{ Standard brass BCS-179-B } \\
\hline Present method & 1.75 & 0.79 & 0.96 & 0.06 & 0.87 & 1.02 & 33.9 & - & 55.5 \\
\hline Certified & 1.75 & 0.78 & 1.01 & 0.06 & 0.91 & 1.06 & 32.5 & - & 58.8 \\
\hline \multicolumn{10}{|l|}{ Standard bronze BCS-183-1 } \\
\hline Present method & 5.05 & 3.39 & 0.48 & 0.51 & - & - & 5.10 & 0.24 & 81.5 \\
\hline Certified & 5.01 & 3.51 & 0.51 & 0.51 & - & - & 5.20 & 0.24 & 84.8 \\
\hline \multicolumn{10}{|l|}{ Standard bronze BCS-183-3 } \\
\hline Present method & 6.73 & 3.42 & 1.48 & 0.03 & 0.03 & - & 3.25 & 0.26 & 82.7 \\
\hline Certified & 6.69 & 3.40 & 1.52 & 0.03 & 0.03 & - & 3.3 & 0.25 & 84.5 \\
\hline Standard Bronze BCS-207-C & & & & & & & 0 & & \\
\hline Present method & 9.79 & 0.40 & 0.09 & 0.05 & 0.06 & - & 2.8 & 0.04 & 83.4 \\
\hline Certified & 9.80 & 0.41 & 0.09 & 0.06 & 0.06 & - & 2.5 & 0.04 & 86.8 \\
\hline \multicolumn{10}{|l|}{ Used bronze-A } \\
\hline Present method & 8.42 & 8.93 & 0.45 & 0.01 & 0.01 & - & - & - & 80.4 \\
\hline Another method & 8.26 & 8.92 & 0.44 & 0.01 & 0.01 & - & - & - & 81.0 \\
\hline \multicolumn{10}{|l|}{ Used Bronze-B } \\
\hline Present method & 9.00 & 7.61 & 0.01 & 0.09 & 0.06 & - & - & - & 80.9 \\
\hline Another method & 8.76 & 7.60 & 0.01 & 0.06 & 0.06 & - & - & - & 81.3 \\
\hline \multicolumn{10}{|c|}{ Standard solder BCS-CRM-No.347 } \\
\hline Present method & 63.1 & 34.2 & - & - & - & - & - & 0.18 & 0.16 \\
\hline Certified & 62.6 & $34.5^{\mathrm{a}}$ & - & - & - & - & - & 0.19 & 0.17 \\
\hline \multicolumn{10}{|l|}{ Used solder } \\
\hline Present method & 59.8 & 40.0 & - & - & 0.03 & - & 0.02 & - & 0.15 \\
\hline Another method & 59.1 & 40.0 & - & - & 0.03 & - & 0.02 & - & 0.14 \\
\hline
\end{tabular}

a. ICP-AES method after separation of tin oxide precipitates. 


\section{References}

1. G. Klenert, Chem. Zig., 77, 471 (1953).

2. K. Mastumoto, M. Nishio, Y. Misaki and K. Terada, Bunseki Kagaku, 31, 141 (1982).

3. K. Matsumoto, H. Koshiishi and K. Terada, Bunseki Kagaku, 33, 237 (1984).

4. C. Yoshimura and Y. Noda, Nippon Kagaku Kaishi, 1978, 561.

5. C. Yoshimura and Y. Noda, Nippon Kagaku Kaishi, 1978, 1098.
6. C. Yoshimura and Y. Noda, Nippon Kagaku Kaishi, 1979, 1497.

7. C. Yoshimura, T. Fujino and T. Yamakoshi, Chem. Express, 8, 209 (1993).

8. K. Satyanarayana and A. Nayeem, At. Spectrosc., 14, 180 (1993).

9. D. A. Wynn, Talanta, 40, 1207 (1993).

10. W. T. Perkins, N. J. Pearce and R. Fuge, J. Anal. At. Spectrom., 7, 611 (1992).

(Received October 20, 1997) (Accepted December 24, 1997) 